\title{
A publicação de revistas eletrônicas: economia da produção, distribuição e uso*
}

\section{Donald W. King Carol Tenopir}

\section{Resumo}

O trabalho analisa aspectos econômicos da publicação de revistas acadêmicas e científicas, baseado em custos de produção e em dados de uso. Compara a producaão de revistas em papel e em formato eletrônico, discutindo as políticas de preços de assinaturas e oferecendo um guia para avaliar o ponto de equilíbrio entre despesa $e$ receita, auxiliando as bibliotecas a optar entre assinar revistas ou obter cópias de artigos mediante serviços de empréstimo interbibliotecas e de comutação bibliográfica.

\section{Palavras-chave}

Publicação de revistas científicas aspectos econômicos; Revista eletrônica versus revista em papel.

\section{INTRODUÇÃO}

\section{Uso, utilidade e valor das revistas acadêmicas e científicas}

Os cientistas freqüentemente lêem revistas acadêmicas para se manter atualizados em suas disciplinas e para aplicar informações em suas pesquisas, no ensino e em outras atividades. Os artigos de revistas acadêmicas são lidos com muito mais freqüência que qualquer outro tipo de publicação, sejam revistas comerciais, livros, relatórios técnicos etc. De fato, os cientistas que trabalham em universidades atingem a média de leitura de 188 artigos por ano, enquanto os cientistas sem vínculo com a universidade lêem 96 artigos em média. Dados obtidos em pesquisas com cientistas indicam que as médias de leitura têm permanecido relativamente constantes durante o período de 1977 a 1996. Um artigo alcança o número médio de 500 a 1500 leituras/ consultas, dependendo do campo da ciência. Dessa forma, uma revista padrão com 123 artigos, publicada em 1995, provavelmente tem bem mais de 100 mil consultas. Entretanto, é importante lembrar que as disciplinas científicas variam de 100 a 100 mil artigos, e a leitura das revistas reflete esse fenômeno.

\footnotetext{
Trabalho apresentado no IV Congresso PanAmericano de Informação em Ciências da Saúde, realizado em San José, Costa Rica, de 25 a 27 de março de 1998. Traduzido e publicado na Ciência da Informação com a permissão dos autores.
}

Os cientistas de universidades usam a informação acadêmica para muitos propósitos: mais de $50 \%$ das consultas objetivam a atualização ou o desenvolvimento profissional, $75 \%$ visam à pesquisa, $41 \%$, ao ensino, e $13 \%$ são para fins administrativos e outros (Tenopir e King ${ }^{1}$ ). Grande parte da informação é muito importante para o ensino e a pesquisa. Das 188 leituras anuais por cientista, 13 são absolutamente essenciais ao ensino e 23 , absolutamente essenciais à pesquisa. Os cientistas de universidades cujas atividades (ensino ou pesquisa) são premiadas ou reconhecidas de forma especial lêem mais do que os cientistas não premiados $(25 \%$ a $33 \%$ mais consultas, dependendo do tipo de trabalho). O valor econômico das revistas acadêmicas pode ser considerado em termos do seu valor de compra, ou seja, do quanto alguém está disposto a pagar pela informação, e por seu valor de uso, em relação aos resultados obtidos com o uso da informação. Não somente esses cientistas pagam em média 3.9 assinaturas por ano, como também "pagam" em média 182 horas do seu tempo lendo essa informação. O tempo dos cientistas é um recurso crítico, assim, a forma como escolhem para empregá-lo é um indicador do valor da atividade na qual esse tempo é investido. Indicadores do valor de uso mostram que $95 \%$ dos leitores indicaram que alguns de seus resultados positivos provieram da leitura de artigos; aproximadamente dois terços indicaram que sua última leitura resultou na melhoria da qualidade da sua pesquisa ou ensino e que os ajudou a desempenhar suas atividades (pesquisa ou ensino) melhor (33\%), mais rápido (19\%), ou resultou no emprego de menos tempo ou dinheiro $(16 \%)$. 
Resultados similares foram observados para cientistas sem vínculo com a universidade (Griffiths e King ${ }^{2}$ ). Nesse caso, o propósito fundamental da leitura de artigos acadêmicos deveu-se à atualização e desenvolvimento profissional (30\% das consultas), pesquisa e desenvolvimento (57\%) e para dar consultoria, escrever ou fazer apresentações (13\%). Essa informação é considerada de grande importância para todas as atividades realizadas pelos cientistas. De fato, quando comparada com seis outros recursos usados em seu trabalho (como instrumentação de laboratórios, calcular, receber orientação de colegas etc.), a informação coletada em documentos é considerada a mais importante ou a segunda mais importante para todas as atividades. Os cientistas premiados lêem $53 \%$ mais artigos que os não premiados, e todos os demais indicadores de desempenho são relacionados ao volume de consultas. Quando os valores monetários são observados, o "valor" de compra de revistas chega a pelo menos US\$ 6 mil por cientista, e o valor de uso é estimado em mais de US\$25 mil. Outros indicadores do valor de uso mostram que o volume de leitura está relacionado a cinco medidas de produtividade, as economias obtidas a partir das leituras são estimadas em cerca de US\$380 por leitura, e uma grande proporção de consultas resulta na melhoria da qualidade da pesquisa, e assim por diante.

Ao longo dos anos, temos procurado demonstrar a utilidade e o valor das revistas acadêmicas a partir de uma série de pontos de vista, todos indicando o quanto essas publicações são essenciais para os cientistas e outros profissionais. A partir da produção de revistas acadêmicas em formato eletrônico, percebemos que é importante que as publicações mantenham a sua qualidade e demais características que contribuem para os altos níveis de uso, utilidade e valor atuais. Na verdade, o potencial das tecnologias de comunicação podem mesmo conduzir, no futuro, a um maior uso, utilidade e valor, se pudermos aprender com os erros do passado e aperfeiçoar nosso conhecimento.

\section{Algumas lições do passado}

Uma lição inequívoca do passado nos ensina que a comunicação através de revistas acadêmicas envolve um sistema de autores, publicadores, serviços de apoio, bibliotecas, leitores e financiadores, além de outros participantes, no qual se observam interdependências sistêmicas e econômicas, em que qualquer tipo de ação pode provocar um efeito reflexivo em todos os seus componentes. As políticas de preço do passado demonstram claramente esse aspecto. Independentemente das razões que levaram à escalada de preços na década de 1970, as conseqüências mostram que as assinaturas pessoais (em particular) começaram a diminuir; os lucros decresceram; os publicadores aumentaram os preços para as bibliotecas; os leitores passaram a depender mais das suas bibliotecas (e de outras) como fonte de artigos a um custo substancial do seu tempo; as bibliotecas começaram, primeiro, a cancelar as assinaturas duplicadas e, depois, a suspender as assinaturas das revistas caras, mas não freqüentemente consultadas, passando a depender de empréstimos interbibliotecas e de serviços de comutação bibliográfica para atender à demanda por esses artigos; os serviços de apoio tornaram-se mais importantes como um meio de identificar e localizar os artigos de interesse. Enquanto isso, o volume de produção autoral e de consultas permanece praticamente o mesmo nos últimos 20 anos.

O aspecto lamentável em tudo isso é que, enquanto os publicadores enfrentam tal situação, as bibliotecas pagam mais por um número menor de revistas e suportam custos crescentes para a obtenção de cópias, assim como os leitores gastam mais de seu tempo para obter artigos, o custo total de todo o sistema de revistas parece, de fato, ter aumentado e se deslocado entre os participantes e processos do sistema. Deveria ter havido formas de evitar essa situação de perdas constantes. Para examinar alternativas para as políticas econômicas do passado, é útil compreender os custos econômicos de publicação, os efeitos das políticas de preços e a mudança nos modelos de distribuição.
Os custos de publicação de revistas geralmente consistem de dois componentes: custos elevados e fixos associados aos processos necessários para produzir a matriz (os originais) de um fascículo de revista; custos menores para reproduzir e distribuir os fascículos. Infelizmente, os publicadores têm relutado em divulgar suas planilhas de custos, de modo que é preciso colher dados fragmentados para saber a extensão desses valores. As evidências sugerem que os custos para produzir, normalizar, editar, compor etc. publicações científicas e acadêmicas podem estar perto de US\$ 4 mil por artigo, quando todos os custos diretos e indiretos são considerados. Os custos de impressão e distribuição são da ordem de US\$ 40 por assinatura. Portanto, preparar a matriz de uma revista com 100 artigos custaria US\$ $400 \mathrm{mil}$ (ignorando as demais matérias da revista). Devido a esse custo elevado e fixo, uma revista com tiragem restrita a mil exemplares exigiria um preço de US\$ 400 para cobrir seu custo de produção, mais US $\$ 40$ para cobrir os custos de impressão e distribuição. À medida que a circulação aumentasse, 0 custo mínimo unitário diminuiria bem rapidamente: US\$80 em 10 mil assinaturas; US\$ 44 em 100 mil assinaturas.

A constituição das disciplinas científicas e as respectivas demandas de informação acadêmica podem variar de umas poucas centenas a centenas de milhares de cientistas. Assim, as revistas tendem a "preparar pacotes" de artigos dirigidos a disciplinas que têm uma abrangência ampla. Isso significa que as revistas que se destinam a pequenas disciplinas devem encontrar formas de reduzir os custos de produção ou terão de cobrar altos preços por seus exemplares. As evidências sugerem que os dois fenômenos ocorrem a um certo nível. Ainda que a média de circulação seja de 5800 assinaturas por título, cerca de $50 \%$ das revistas tem menos de 1900 assinantes, e um número substancial de publicações tem menos de mil assinantes. Isso explica parcialmente por que tantas revistas têm preços altos. Além disso, os custos aumentaram porque as revistas aumentaram substancialmente o número de artigos, páginas e fascículos. 
Por outro lado, as estratégias de preços têm contribuído para o aumento em espiral desses valores, provocando uma circulação menor que, por sua vez, gera preços ainda mais altos. Está suficientemente claro que indivíduos e pequenas organizações, em particular, não estão dispostos a pagar por revistas caras e de uso pouco freqüente, uma vez que eles têm a opção de ir a bibliotecas (e a outros lugares) e ter acesso às revistas ou aos artigos de que precisam, de forma menos onerosa. As assinaturas com base nesses aspectos são altamente suscetíveis a mudanças de preços, porque o pequeno volume de consulta significa que o custo por consulta é relativamente alto e, nesses casos, pode ser bem menor, optando-se pela biblioteca. E mais, uma vez que as revistas têm uma consulta relativamente alta (e crescente) nas grandes bibliotecas, freqüentemente é mais barato (por leitura) assinar do que emprestar; mesmo assim, os preços das assinaturas estão aumentando. Portanto, as assinaturas para as grandes bibliotecas são bem menos suscetíveis aos aumentos de preços.

O custo de publicação das revistas eletrônicas será menor que o da versão tradicional em papel, mas nem tanto assim. Grande parte dos custos de produção de um artigo será a mesma, ainda que um pouco menor, a não ser que alguns processos de agregação de valor sejam suspensos ou modificados. Os custos de reprodução e distribuição serão substituídos pelo armazenamento e distribuição eletrônicos, que são muito menos dispendiosos. Entretanto, os custos de reprodução e estocagem da versão em papel são pequenos comparados aos custos fixos da maioria das revistas científicas, e os publicadores devem ainda reaver os grandes custos de produção da matriz. O que pode mudar são as formas pelas quais os artigos são fornecidos e como os publicadores estabelecem preços por seus serviços.

A Internet e outras tecnologias de comunicação abrem uma série de possibilidades para serviços de distribuição de novos artigos. Para começar, os publicadores serão capazes de oferecer uma base de dados de revistas, revistas individuais, artigos individuais ou partes de artigos. Vários níveis de infor- mação podem tornar-se disponíveis para consulta, incluindo títulos, resumos, revisões do artigo, dados complementares, apêndices etc. Conjuntos de artigos poderiam ser enviados automaticamente para os leitores baseados em perfis de interesse dos usuários. A qualidade dos artigos mais antigos pode ser medida pelo número de citações de autores (antes ou depois da publicação), por avaliações feitas pelos leitores ou por uma comissão de especialistas. Uma vez que quaisquer dessas mudanças afetarão os custos, as características da informação e dos serviços, o uso e as estratégias de preços devem ser determinados para cada uma.

Diferentes produtos como os anteriormente mencionados exigirão preços distintos também. Contudo, uma outra forma de discriminação de valores pode igualmente ser adotada para evitar o aumento constante de preços observado nas duas últimas décadas. Pelo menos, alguns dos problemas poderiam ter sido evitados se indivíduos ou bibliotecas que atendem a pequenos grupos de indivíduos tivessem pago menos do que as grandes bibliotecas, nas quais a consulta de revistas é alta. Não parece fazer sentido cobrar US $\$ 500$ de um leitor por uma revista que é consultada, digamos, dez vezes (isto é, US\$ 50 por leitura), e cobrar o mesmo valor de uma biblioteca, na qual a revista é consultada 100 vezes (isto é, US $\$ 5$ por leitura). O indivíduo irá cancelar a assinatura e usar uma cópia fornecida pela biblioteca, assim negando os lucros do publicador, fazendo com que o leitor perca o seu tempo e custando à biblioteca uma pequena quantia para administrar seu uso. No caso das versões em papel, seria melhor cobrar US\$ 40 de um indivíduo por conta da reprodução e distribuição, mais uma certa quantia pela consulta, digamos, US\$ 5 , somando US\$90 e, desse modo, oferecendo US $\$ 40$ de lucros que poderiam ser aplicados aos custos fixos. No caso das revistas eletrônicas, quase a totalidade dos US $\$ 90$ poderia ser aplicada aos custos fixos, sendo que a circulação e os ganhos aumentariam e os preços da assinatura para bibliotecas cairiam (prevendo-se que alguma consulta também cairá). Portanto, formas de discriminação de preços baseadas em consultas reais ou potenciais poderiam fazer sentido. Esse tipo de estratégia levaria a uma condição de ganhos constantes que pode ser alcançada porque as tecnologias eletrônicas podem ajudar no controle e no estabelecimento de mecanismos satisfatórios de pagamento. A seguir, essa conclusão é desenvolvida em detalhes.

\section{Economia da produção de revistas eletrônicas}

\section{Custo econômico da produção}

Poucos dados têm sido divulgados sobre os custos da publicação tradicional de revistas, sem contar a publicação eletrônica, que podem ser mal interpretados devido a duas razões básicas:

- Freqüentemente, os custos são considerados enquanto proporções entre a produção da matriz (antes da impressão) e a impressão e distribuição (por exemplo, $80 \%$ dos custos são devidos à matriz e $20 \%$, à impressão e distribuição). O problema com essa abordagem é que as proporções dependem grandemente da circulação (e, em menor grau, de outras variáveis como o número de artigos, páginas etc.). Por exemplo, supondo que o custo de uma matriz seja de US\$ 400 mil e que os custos de impressão e distribuição sejam de US\$ 40 por assinatura, uma revista com mil assinaturas teria as proporções de $91 \%$ para a matriz e $9 \%$ para a impressão e distribuição. Uma revista com 100 mil assinaturas teria proporções exatamente opostas: $9 \%$ para a matriz e $91 \%$ para a impressão e distribuição.

- Os dados registrados sobre os custos de produção têm oscilado de US $\$ 200$ a US\$ 8 mil por artigo. Parece claro que tais dados não mostram o que esses custos cobrem.

Para tratar desses dois problemas, elaboramos um modelo dos custos econômicos de publicação de revistas, subdividido em quatro funções básicas: 1) processamento de artigos; 2) impressão e distribuição; 3) processamento de outras matérias (exceto artigos); 4) serviços de apoio para publicação. 
O processamento de artigos inclui todas as atividades de edição que começam com o recebimento de um manuscrito e terminam com a composição e o molde da matriz: processo de recebimento, identificação de revisores/ pareceristas, processo de revisão, edição de texto, preparação gráfica especial ou outra, formatação, edição da cópia, aprovação do autor, redação e preparação de matrizes de imagens. A maioria das atividades é planejada para melhorar as características favoráveis da informação contida no artigo e da sua apresentação. Os custos comuns do processamento de artigos de revistas acadêmicas e científicas tradicionais são da ordem de US\$2 mil por artigo ou cerca de US\$ 165 por página publicada.

Acreditamos que a maioria das atividades do processamento de artigos realizadas em revistas tradicionais deverá também ser feita no caso de revistas eletrônicas. As maiores reduções de custos alcançadas pelas revistas eletrônicas parecem residir nos custos de composição, sendo que a economia aqui seria no máximo da ordem de $10 \%$. Defensores da publicação eletrônica sugerem que as reduções de custos podem ser alcançadas através da transmissão via Internet e do processamento eletrônico de manuscritos, mas isso também pode ser obtido com publicações tradicionais. A duração do processo de publicação pode ser reduzida por meio da transmissão eletrônica, mas não muito porque os atrasos de tempo se devem em grande parte à intervenção humana (isto é, edição, revisão etc.). A revista eletrônica mantém também uma taxa de custos muito baixa por artigo (ou seja, comumente entre US\$ 200 e US\$500). Não se sabe por que esses custos são tão baixos, mas pode ser que alguns recursos sejam concessões. Entretanto, uma razão mais plausível aponta para o fato de que essas revistas de baixo custo não incorporam todos os processos de produção encontrados nas revistas mais estabelecidas. Observamos que pequenas revistas têm uma tendência para custar menos que as grandes revistas (ou seja, os custos unitários são menores), mesmo para as revistas tradicionais.
FIGURA 1

Preço mínimo necessário em vários níveis de circulação, a um custo fixo de US $\$ 403.500$ e um custo variável de US $\$ 40$ por assinatura (em cotações de 1995)

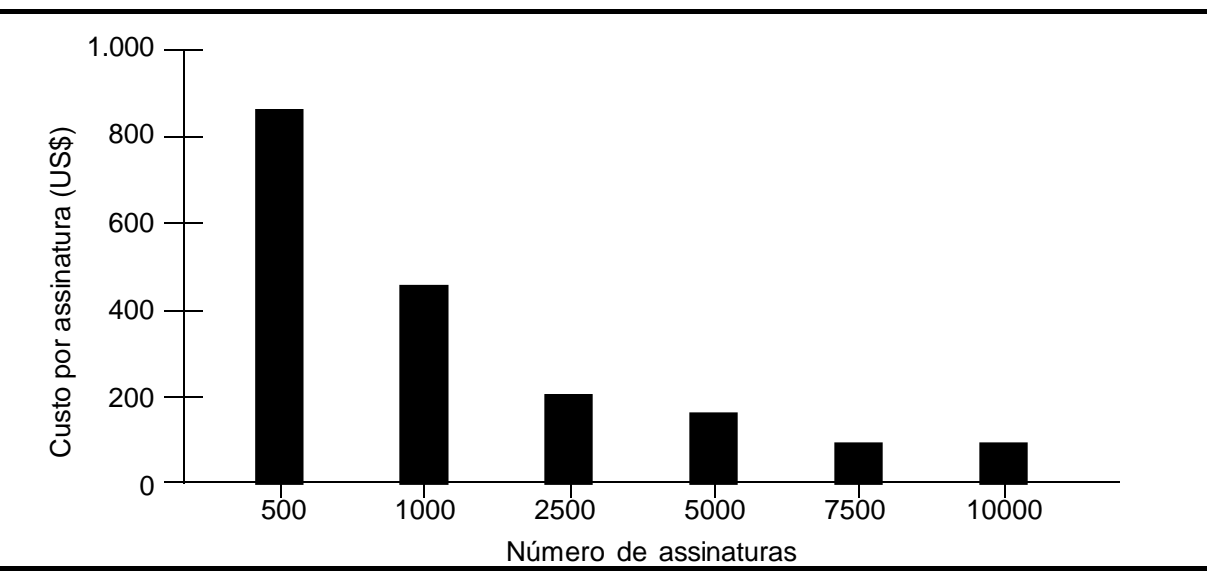

Para as revistas em papel, os custos de impressão incluem a elaboração de fotolito, composição, leiaute, impressão, paginação e encadernação. Os custos usuais são da ordem de US\$25 por revista por ano, lembrando que esses custos variam de acordo com o número de artigos, páginas, fascículos, qualidade do papel e da encadernação etc. Os custos de distribuição incluem o processo de envio (envelopar, organizar, etiquetar, selar etc.), postagem e controle de assinaturas. Os custos normais são de aproximadamente US\$15 por assinatura, novamente, lembrando que o número de fascículos, peso etc. têm relação direta com os custos. Esses custos são muito menores no caso das revistas eletrônicas, que exigem armazenamento eletrônico (mas não impressão). No entanto, as reduções de custos atribuíveis à publicação eletrônica provavelmente não são muito mais do que aproximadamente US\$ 35 por assinatura. Portanto, uma revista de US\$500 custaria apenas 7\% menos, permanecendo iguais todas as demais características.

O processamento de outras matérias (exceto artigos) abrange essencialmente as mesmas atividades do processamento de artigos e inclui capas, sumários, editoriais, resenhas de livros, cartas ao editor e publicidade, entre outras. A longo prazo, não está totalmente claro se tais informações serão incluídas nas revistas eletrônicas. Atualmente, as revistas acadêmicas e científicas alcançam a média de 290 páginas por ano de outras matérias que não artigos (comparada a 1439 páginas de artigos). Os custos do processamento de outras matérias chegam a cerca de US $\$ 100$ por página (comparados a US\$165 por página de artigo). Os serviços de apoio para publicação incluem marketing e promoção (como publicidade, catálogos etc.), administração (pessoal, contabilidade e outros recursos), controle e proteção de direitos autorais, financiamento (como pesquisa e desenvolvimento de novos produtos, pagamentos de benefícios, capitalização, pagamento de impostos etc.) e outros custos indiretos (seguro, taxas, estacionamento, viagens etc.). Esses custos tendem a alcançar cerca de $40 \%$ dos custos de processamento de artigos e de outras matérias e $21 \%$ dos custos de impressão e distribuição. Portanto, novamente, os custos dos serviços de apoio podem não ser muito menores para as revistas eletrônicas em relação às revistas tradicionais.

Uma revista acadêmica e científica padrão teria um custo fixo perto de US\$ 403.500 e um custo variável de cerca de US\$ 40 por assinatura (em cotações de 1995 -Tenopir e King ${ }^{3}$ ). O preço mínimo necessário para recuperar os custos de publicação, dependendo dos níveis de circulação, seria o seguinte: com 500 assinaturas, o preço mínimo seria de US\$847, caindo para quase a metade, ou US\$444, com mil assinaturas; com 10 mil assinaturas, o preço cairia para US\$80 (figura 1). A questão fundamental aqui é que esses custos não serão reduzidos substancialmente com o advento da publicação eletrônica, se todos os aspectos das revistas permanecerem os mesmos. O preço referente a 500 assinaturas cairia cerca de US $\$ 110$ (de US $\$ 847$ para US\$ 738), mas seria a metade com 10 mil assinaturas (de US\$80 para US\$42). 
Pode ser que a Internet e serviços complementares venham a afetar a produção de publicações de outros modos mais importantes do que na redução dos custos das revistas. As novas tecnologias podem oferecer a flexibilidade de acesso a múltiplos produtos editoriais, como vender uma base de dados de revistas, revistas individuais, artigos individuais, páginas ou parágrafos de artigos. Outros tipos de produtos podem incluir inicialmente versões preliminares (preprints) de artigos e, depois, versões editadas; a qualidade dos artigos pode ser avaliada (por número de citações de autores, pelos leitores, por uma comissão de especialistas etc.); conjuntos de artigos podem estar acessíveis ou ser enviados automaticamente para os leitores baseados em perfis de interesse (como na disseminação seletiva da informação); ou vários níveis de informação contida no artigo podem ser consultados, como títulos, resumos, revisões, textos completos, dados complementares, apêndices etc.

\section{Estabelecendo preços para a revista eletrônica}

É praticamente indiscutível que os preços das revistas aumentaram de modo considerável nos últimos 20 anos $\left(\right.$ Tenopir e King ${ }^{3}$ ). Estima-se que os preços das revistas acadêmicas e científicas norte-americanas aumentaram de US\$ 39 em média no ano de 1975 para US\$ 284 em 1995. Portanto, os preços médios aumentaram em um fator de 7.3 , ou 2.6 vezes em uma taxa monetária constante. Parte dessa majoração de preços é atribuída ao aumento no tamanho das revistas (tabela 1). Entretanto, esses acréscimos respondem por uma proporção relativamente pequena do total de aumentos. Uma explicação muito mais plausível é que inicialmente os aumentos de preços nesse período de 20 anos ocorreram devido à inflação alta, à flutuação das taxas de câmbio internacionais e aos cortes feitos por empresas e agências nas verbas disponíveis para assinaturas. Uma vez que os preços ultrapassaram a taxa de inflação, as assinaturas começaram a diminuir, particularmente as assinaturas pessoais. De fato, as assinaturas feitas por cientistas norte-americanos caíram de uma média de 5.8 assinaturas por indivíduo em 1975 para 2.9 em 1995. Enquanto o número total de assi-

TABELA 1

\section{Parâmetros de publicação de revistas acadêmicas}

\begin{tabular}{lrr}
\hline Parâmetros do modelo de custos & $\mathbf{1 9 7 5}$ & $\mathbf{1 9 9 5}$ \\
\hline Número de fascículos & 6.5 & 8.3 \\
Número de artigos/títulos & 85 & 123 \\
Número de manuscritos apresentados para publicação & 90 & 205 \\
Número de páginas de artigos & 630 & 1.434 \\
Número de páginas especiais & 114 & 260 \\
Número total de páginas & 820 & 1.723 \\
Número de assinaturas & 6.100 & 5.800 \\
\hline
\end{tabular}

Fontes: King et al..$^{7}$ e Tenopir e King ${ }^{3}$.

\section{TABELA 2}

\section{Número médio de consultas das revistas acadêmicas e científicas por cientista por ano}

\begin{tabular}{lrrrr}
\hline & 1977 & 1984 & $1985-1990$ & $1991-1997$ \\
\hline Cientistas de universidades & 150 & 172 & - & 188 \\
Cientistas sem vínculo com universidades & 90 & 99 & 90 & 96
\end{tabular}

Fontes: King et al. ${ }^{7}$ e Tenopir e King ${ }^{1}$ (dados de 1977 e 1984, obtidos em pesquisas nacionais, e de 1985-1997, em pesquisas realizadas em instituições).

naturas cresceu durante esse período, a média de circulação por título diminuiu, resultando em perdas anuais de bilhões de dólares em lucros para os publicadores.

Como resultado da diminuição nos lucros devido à redução das assinaturas pessoais, os publicadores aumentaram ainda mais os preços das assinaturas institucionais para compensar as perdas financeiras. Demonstramos que essa estratégia tem alcançado certo êxito porque a demanda institucional por revistas é substancialmente menos suscetível a mudanças de preços do que a demanda por assinaturas pessoais (Tenopir e King ${ }^{3}$ ). Por exemplo, para uma base de 2500 assinaturas, aumentar o preço de US\$150 para US $\$ 250$ reduziria potencialmente as assinaturas individuais na ordem de 1800 ; enquanto a circulação institucional cairia somente 200 assinaturas. O problema é que as estratégias de preços que levaram à atual "crise" resultaram em lucros menores para os publicadores e em custos maiores para os indivíduos, bibliotecas e mantenedores de bibliotecas e seus usuários (ou seja, perdas sucessivas).

Os publicadores de revistas eletrônicas podem manter as políticas atuais de preços e simplesmente cobrar por assinaturas on-line, talvez a um preço mais baixo. Entretanto, as novas tecnologias podem flexibilizar a distribuição, como mencionado anteriormente, sugerindo também novas estratégias de preços e novos mecanismos de pagamento $\left(V_{a r i a n^{4}}{ }^{K_{\text {King }}}{ }^{5}\right)$. É provável que o estabelecimento de preços para as revistas eletrônicas mude para outras formas de cálculo baseadas em diferentes produtos e em suas quantidades (quer dizer, várias revistas, uma revista, artigo, página etc.), nos meios de distribuição (papel, on-line, formas combinadas), nas características dos serviços (como processamento variável ou regular) e na personalização da clientela (preprints e versões editadas etc.). Preços diferenciais podem também incluir classes de consumidores baseadas em potenciais de leitura. Os mecanismos de pagamento também podem ser adaptáveis à oferta de serviços e às necessidades dos usuários $\left(\right.$ Sirbu $\left.^{6}\right)$.

\section{Economia da distribuição}

Tanto o volume de produção autoral como o de consultas de revistas acadêmicas têm permanecido constantes de 1975 a 1995. Por exemplo, havia cerca de 0.118 artigos publicados por cientista (nos Estados Unidos) por ano em 1975, e esse número era de 0.101 artigos em 1995. Mesmo assim, o número médio de assinaturas por cientista caiu pela metade; as evidências sugerem que a consulta não diminuiu (tabela 2). Ao 
invés disso, tem havido uma mudança dramática no tipo de fonte dos artigos (tabela 3). Grande parte dessa mudança nas fontes ocorre das assinaturas pessoais para as revistas assinadas pelas bibliotecas. Em 1977, cerca de $25 \%$ das consultas de cientistas de universidades foram realizadas a partir de coleções pertencentes a bibliotecas (dados baseados em uma pesquisa nacional), mas esse número aumentou para $54 \%$ (baseado em uma pesquisa realizada em 1993 pela Universidade do Tennessee). No caso dos cientistas sem vínculo com a universidade, a proporção cresceu de $10.4 \%$ para $37.4 \%$ (dados baseados em pesquisas sobre cientistas de sete companhias).

É evidente que as bibliotecas são utilizadas muito mais agora para consulta do que no passado. Aproximadamente todos os cientistas de universidades (97\%) afirmam que consultam a coleção de revistas de suas bibliotecas, assim como $69 \%$ dos cientistas sem vínculo com universidades. Uma das razões para isso é que o aumento de preços levou os cientistas a cancelar suas assinaturas e a depender das coleções de bibliotecas para obter seus artigos. As evidências mostram que eles estão dispostos a investir seu tempo para ir à biblioteca, em vez de pagar altos preços por uma revista, mesmo que a sua instituição venha a pagar por ela (Tenopir e King ${ }^{3}$ ). Eles claramente compensam seus custos assinando revistas de preços baixos que lêem com freqüência e consultando a biblioteca para ter acesso a revistas caras que lêem ocasionalmente. De fato, do ponto de vista do custo por leitura, os cientistas geralmente fazem suas escolhas segundo uma lógica econômica; ou seja, o custo médio por consulta para usar uma revista da biblioteca é em torno de US\$ 11.50 por leitura. Portanto, deve haver pelo menos 33 consultas de uma revista de US\$250 para que uma assinatura pessoal tenha valor (considerando o preço, os custos de processamento e de acesso). Para uma revista de US\$1 mil, deveria haver ao menos 128 consultas. Assim, o número médio de consultas relativas a assinaturas pessoais é de apenas 18.8 leituras por revista por cientista.

\section{TABELA 3}

Tendências na proporção de consultas de artigos acadêmicos e científicos feitas por cientistas de universidades e sem vínculo com universidades

\begin{tabular}{lrrrrrrr}
\hline $\begin{array}{l}\text { Fontes dos } \\
\text { artigos }\end{array}$ & \multicolumn{3}{c}{$\begin{array}{l}\text { Cientistas de } \\
\text { universidades }\end{array}$} & \multicolumn{3}{c}{$\begin{array}{c}\text { Cientistas sem vínculo } \\
\text { com universidades }\end{array}$} \\
\hline & 1977 & 1984 & 1993 & 1977 & 1984 & $1985-$ & $1991-$ \\
& $\%$ & $\%$ & $\%$ & $\%$ & $\%$ & $\%$ & $\%$ \\
& 60.0 & 53.0 & 35.5 & 72.0 & 66.3 & 43.9 & 40.1 \\
Assinatura pessoal & 24.8 & 30.1 & 53.8 & 10.4 & 20.5 & 32.1 & 37.4 \\
Coleções de bibliotecas & 15.2 & 16.9 & 10.7 & 17.6 & 13.2 & 24.0 & 22.5 \\
Outros (autor etc.) & 100.0 & 100.0 & 100.0 & 100.0 & 100.0 & 100.0 & 100.0 \\
Total & & & & & & &
\end{tabular}

Fontes: King et al. ${ }^{7}$, Tenopir e King ${ }^{1}$ (dados de 1977 e 1984 obtidos em pesquisas nacionais, e de 1985-1997, em pesquisas realizadas em instituições).

\section{TABELA 4}

Volume de consultas referente ao ponto de equilíbrio entre despesa e receita baseado na assinatura e no custo da obtenção de cópias de artigos: um guia para revistas individuais

\begin{tabular}{lrrrrrrr}
$\begin{array}{l}\text { Preço da } \\
\text { assinatura (US\$) }\end{array}$ & \multicolumn{5}{c}{$\begin{array}{l}\text { Obtenção de cópias } \\
\text { Custo unitário (US\$) }\end{array}$} \\
\hline & 5 & 10 & 15 & 20 & 25 & 30 & 35 \\
100 & 47 & 20 & 13 & 9 & 7 & 6 & 5 \\
250 & 89 & 37 & 24 & 17 & 14 & 11 & 10 \\
500 & 158 & 66 & 42 & 31 & 24 & 20 & 17 \\
750 & 228 & 95 & 60 & 44 & 38 & 29 & 24 \\
1.000 & 297 & 124 & 79 & 58 & 45 & 37 & 32 \\
1.250 & 367 & 153 & 97 & 71 & 56 & 46 & 39 \\
1.500 & 436 & 183 & 115 & 84 & 67 & 55 & 47 \\
\hline
\end{tabular}

Acima do ponto de equilíbrio, a biblioteca deve assinar uma revista, e abaixo dele, a biblioteca deve optar pelas cópias.

No caso das revistas eletrônicas, é possível aplicar uma análise de custos similar para orientar ou oferecer diretrizes aos usuários sobre se devem assinar uma revista (em papel ou em formato eletrônico), ou adquirir cópias on-line individuais. Da mesma forma, se uma biblioteca pode dispor de revistas e oferecer cópias de artigos através de redes locais, é possível demonstrar um custo equilibrado similar entre o uso dessas revistas comparado com a aquisição de assinaturas pessoais.

As bibliotecas também enfrentam a opção de assinar revistas ou obter cópias individuais através do empréstimo interbibliotecas ou de serviços de comutação bibliográfica (em fotocópias ou em formato eletrônico). A escolha se resume em assinar revistas de baixo custo com índices freqüentes de consulta e obter cópias dos artigos de revistas muito caras mas pouco consultadas. Em geral, incluindo todas as atividades, os custos de uma biblioteca para processar uma revista são de US\$70 por assinatura e em média US\$1.40 por consulta para armazenar os fascículos e/ou copiar um artigo (Tenopir e King ${ }^{3}$ ). O custo total do uso de serviços de empréstimo interbibliotecas ou de comutação está na faixa entre US\$15 e US\$25 por item transacionado. É possível calcular o balanço entre despesa e receita da consulta conhecendo-se 0 preço de uma revista (e os custos do seu processamento) e o custo da obtenção de cópias de artigos. O problema é que o custo do acesso eletrônico varia dramaticamente entre os provedores. Por essa razão, oferecemos um guia para avaliar o ponto de equilíbrio entre despesa e receita baseado no preço da assinatura (mais os custos de processamento mencionados anteriormente) e no custo unitário da obtenção de cópias de artigos (esse guia encontrase na tabela 4). Por exemplo, uma revista cujo preço é de US\$250 exigiria 
pelo menos 17 consultas se a obtenção de cópias custar US\$20. Chegando em US\$ 5, o ponto de equilíbrio entre despesa e receita é 89 , e em US\$ 35, o ponto de equilíbrio é de 10 consultas. Portanto, em um determinado preço de assinatura, o ponto de equilíbrio diminui à medida que o custo da obtenção de cópias aumenta. Se a escolha se encontra entre fazer uma assinatura eletrônica e usar um serviço eletrônico de fornecimento de cópias, a análise de equilíbrio é similar, lembrando que os custos de processamento são provavelmente menores nos dois casos.

O número médio de consultas das revistas pertecentes às bibliotecas parece ser aproximadamente 150 leituras por revista (durante o seu período de vida). O exame da tabela 4 mostra que, mesmo a um preço de US\$1500, uma revista de consulta média (150 leituras) deve ser assinada se o custo da obtenção de cópias for maior que US\$ 15 por cópia. Entretanto, a consulta de revistas em bibliotecas tende a variar enormemente; quer dizer, poucas revistas são consultadas com grande freqüência e muitas revistas são lidas poucas vezes. Por exemplo, vários estudos mostram que cerca de $50 \%$ das revistas pertencentes a bibliotecas são consultadas menos que 50 vezes, apenas $25 \%$ são consultadas mais que 150 vezes e $15 \%$ têm mais de 250 consultas.
Baseados nos custos previstos de revistas eletrônicas, acreditamos que algumas revistas perderão assinaturas tradicionais, passando a depender muito mais intensamente dos lucros advindos da distribuição de separatas. É provável que essas revistas sejam aquelas mais caras que geralmente atendem uma pequena comunidade de estudiosos. No entanto, os publicadores que fizerem isso devem estar dispostos a cobrar uma quantia que cobrirá os custos tanto dos artigos freqüentemente solicitados, como os dos artigos menos consultados. Isso, é claro, é o que o "o preparo de pacotes" de artigos em revistas tradicionais faz agora. De outro modo, os artigos de alta qualidade que interessam a um pequeno público estarão perdidos para o processo de publicação.

\section{REFERÊNCIAS BIBLIOGRÁFICAS}

1. TENOPIR, C., KING, D.W. The transformation of scientific scholarly journals: trends in the economics, production, information seeking, and use. [in press]

2. GRIFFITHS, J.M., KING, D.W. Special libraries: increasing the information edge. Washington: Special Libraries Association, 1993.

3. TENOPIR, C., KING, D.W. Trends in scientific scholarly publishing. Journal of Scholarly Publishing, v. 48, n. 3, p. 135-70, 1997.

4. VARIAN, H.R. Differential pricing and efficiency. First Monday: peer-reviewed journal on the Internet [online], Chicago, v.1, n. 2, Aug. 1996. [http:// www.firstmonday.dk/issues/issue2/ different/]

5. KING, D.W. Some economic aspects of the Internet. Journal of the American Society for Information Science, Apr. 1998. [in press]

6. SIRBU, M.A. Creating an open market for information. The Journal of Academic Librarianship, Managing Technology Issue, p. 467-71, 1995

7. KING, D.W., MCDONALD, D.D., RODERER, R.K Scientific journals in the United States: their production, use, and economics. Stroudsbourg, PA: Hutchinson Ross Publishing, 1981.

\section{Electronic journal publishing: economics of production, distribution, and use}

\author{
Abstract \\ This paper analyses economic aspects of \\ the scientific scholarly journal publishing, \\ based on production costs and use data. It \\ compares the production of traditional \\ journals with electronic journals, discussing \\ price policies for subscriptions and \\ providing a guide to assess breakeven \\ points, helping libraries to face the option of \\ subscribing to journals or obtaining \\ separate copies through interlibrary \\ borrowing or document delivery.
}

\section{Keywords}

Scientific scholarly journal publishing -

Economic aspects; Eletronic journals versus traditional journals.
Donald W. King

School of Information Sciences, University of Tennessee.

dwking@umich.edu

\section{Carol Tenopir}

School of Information Sciences, University of Tennessee.

Tradução do inglês de Irati Antonio. 